\title{
Kernos
}

Revue internationale et pluridisciplinaire de religion grecque antique

$23 \mid 2010$

Varia

\section{Thomas Heine NIELSEN, Olympia and the Classical Hellenic City-State Culture}

\author{
Vinciane Pirenne-Delforge
}

\section{OpenEdition \\ Journals}

\section{Édition électronique}

URL : http://journals.openedition.org/kernos/1628

DOI : $10.4000 /$ kernos. 1628

ISSN : 2034-7871

\section{Éditeur}

Centre international d'étude de la religion grecque antique

\section{Édition imprimée}

Date de publication : 1 janvier 2010

Pagination : 381-382

ISSN : 0776-3824

\section{Référence électronique}

Vinciane Pirenne-Delforge, «Thomas Heine nielsen, Olympia and the Classical Hellenic City-State Culture », Kernos [En ligne], 23 | 2010, mis en ligne le 15 septembre 2011, consulté le 21 septembre 2020. URL : http://journals.openedition.org/kernos/1628; DOI : https://doi.org/10.4000/kernos.1628

Ce document a été généré automatiquement le 21 septembre 2020.

Kernos 


\title{
Thomas Heine NIELSEN, Olympia and the Classical Hellenic City-State Culture
}

\author{
Vinciane Pirenne-Delforge
}

\section{RÉFÉRENCE}

Thomas Heine NIELSEN, Olympia and the Classical Hellenic City-State Culture, Copenhague, The Royal Danish Academy of Sciences and Letters, 2007. 1 vol. $15 \times 23 \mathrm{~cm}, 139$ p. (Historik-filosofiske Meddelelser, 96). ISBN : 978-87-7304-309-7.

1 Cet intéressant petit ouvrage a été conçu dans l'orbe du Copenhague Polis Center. Un détail le confirme : chaque fois que le nom d'une cité apparait dans le texte, il est suivi de son numéro d'ordre dans le classement du célèbre centre danois de recherche sur la cité... Au-delà de l'anecdote, l'exploitation qui est ici faite des acquis des travaux patronnés par Mogens Hansen aboutit à une synthèse, brève mais efficace, sur l'importance d'olympie comme centre d'interaction entre les cités grecques et comme lieu d'expression de la différence entre Grecs et Barbares. Les aspects proprement religieux du sanctuaire ne sont guère abordés. Néanmoins, ceux qu'intéressent plus particulièrement de telles questions trouveront leur profit à cette lecture qui permet d'inscrire le lieu de culte dans l'ensemble culturel et politique auquel il appartient. Vu que l'introduction et la conclusion sont numérotées elles aussi - une curieuse pratique qui se généralise, - le premier chapitre est en fait le chapitre II et se fonde essentiellement sur Hérodote pour montrer combien la pratique athlétique était conçue comme une marque distinctive de l'hellénisme. Le chapitre III étaie l'hypothèse que l'accès aux concours d'Olympie était exclusivement réservé aux Grecs, tandis que le chapitre IV revient (trop) brièvement sur la question complexe de la nudité athlétique. Le chapitre $\mathrm{V}$ analyse plus longuement l'implication de la cité d'Élis dans l'administration d'Olympie. Enfin, le chapitre VI aborde la question centrale de 
l'interaction entre Grecs, essentiellement traitée dans cette dernière partie de livre, qui couvre ainsi un peu moins de la moitié de l'ensemble.

2 La tension entre unité et diversité qui traverse toute l'histoire grecque est au cœur de la problématique analysée par l'A. À Olympie, la culture des cités-États trouvait à affirmer à la fois sa diversité (les athlètes étaient identifiés par l'une des quelque mille cités répertoriées, autant d'entités farouchement attachées à leur spécificité) et un sentiment de similarity que les concours permettaient d'affirmer, par la réitération de la distinction entre Grecs et Barbares. Hérodote l'affirmait déjà dans le passage célèbre du livre VIII (144) définissant to Hellenikon. À côté de la même langue, du même sang, des mêmes coutumes apparaissent «des sanctuaires communs et des sacrifices" qui évoquent les lieux de culte panhelléniques comme Olympie. D'autres sanctuaires " communs » étaient tout autant, mais sous d'autres modalités, des lieux d'affirmation de la «culture des cités-États » et il faudrait peut-être nuancer, davantage que ne le permet la brièveté de l'argument, la position dominante d'olympie en cette matière.

\section{AUTEURS}

VINCIANE PIRENNE-DELFORGE

F.R.S.-FNRS - Université de Liège 